\title{
Dipyridamole is superior to dobutamine for thallium stress imaging: a randomised crossover study
}

\author{
Easwar B Kumar, Susan A Steel, Syd Howey, John L Caplin, Clive P Aber
}

\begin{abstract}
Objective-To assess the value of dobutamine over dipyridamole as a pharmacological stressing agent in myocardial perfusion imaging with thallium-201.

Design-Stress and redistribution tomographic images were taken in a group of patients in a randomised crossover study of both agents. The scans were scored to give a value for the stress and redistribution images and a reversibility score (redistribution - stress). All patients had coronary angiography that was also scored. Differences between the two agents were compared by a paired $t$ test. Patients-30 patients aged 51-70 years with chest pain thought to be caused by myocardial ischaemia. 11 had had previous myocardial infarction.
\end{abstract}

Results-Dipyridamole caused adverse symptoms in six patients whereas dobutamine caused symptoms in 21 patients $\left(\chi^{2}=15.15, \quad \mathrm{p}<0.0001\right)$. Dobutamine stress took considerably longer than dipyridamole (31 $v 6$ minutes) and cost more $(£ 17 v £ 1 \cdot 50)$. There were no significant differences between the agents in terms of total stress or redistribution scores, but regional analysis showed that dipyridamole showed significantly more defects during stress at the apex and lateral wall ( $p<0.05$ ), with no significant difference at redistribution. Dipyridamole stress also caused significantly more reversible defects at the apex $(p<$ 0.05 ) and gave a better correlation than dobutamine with coronary score (dipyridamole $r=0.80, p<0.001 v$ dobutamine $r=0.64, p<0.001)$. In six patients who had continued to take $\beta$ blockers the results of dobutamine stress did not correlate with coronary score, $r=0.34$ (NS), whereas dipyridamole studies were not affected.

Conclusion-Compared with dobutamine, dipyridamole was as effective in producing overall perfusion defects and more effective in provoking defects at the apex and lateral segment. The dipyridamole study correlated better with coronary score and was not affected by concurrent $\beta$ blocker treatment. It was also better tolerated by the patients, was less time consuming, and was much cheaper.

(Br Heart f 1994;71:129-134)
Thallium-201 imaging with dipyridamole stress is an established alternative to dynamic exercise in the radionuclide assessment of myocardial ischaemia. ${ }^{1}$ The technique relies primarily on the responses of normal and diseased coronary arteries to dipyridamole resulting in differential blood flow in these vessels. In most instances, there is little change in heart rate or blood pressure ${ }^{2}$ and perfusion abnormalities detected with this technique probably indicate areas of altered blood flow rather than areas of ischaemia. ${ }^{3-5}$ In view of this limitation, dobutamine has been promoted as a better pharmacological stressing agent because its effect on contractility, rate-pressure product, and myocardial oxygen demand more closely parallels that of dynamic exercise. ${ }^{6}$ Furthermore, there is evidence that perfusion defects detected during a dobutamine thallium study do indicate underlying myocardial ischaemia. ${ }^{7}$

To assess this, thallium studies were performed with both drugs in a group of patients with angina. The diagnostic accuracy of each drug in the detection of coronary artery disease was also assessed by relating the scans to the results of coronary angiography.

\section{Patients and methods}

STUDY PATIENTS

We studied 24 men and six women (mean (SD) age $58 \cdot 4(5 \cdot 3)$ years, range 51-70). All patients were selected for enrolment in the study because they had chest pain thought to be caused by myocardial ischaemia. Eleven had had a previous myocardial infarction, which was sited anteriorly in two patients, inferiorly in six, and was indeterminate in location in one. The time interval from myocardial infarction to first study was more than two years in seven patients whereas in the other four, the intervals were two months, 10 months, 11 months, and 16 months. Four patients were in New York Heart Association class III, 15 were in class II, and 11 were in class I. No patient had unstable angina. Only three had never smoked and the rest were either current smokers or had recently stopped.

\section{STUDY PROTOCOL}

All patients underwent thallium-201 single photon emission computed tomography (SPECT) on two occasions, once with dipyridamole as the pharmacological stressing agent and once with dobutamine, in random
HU3 2JZ, North

Accepted for publication

22 September 1993 
order. They received the same instructions, to have only a light breakfast and no caffeine for 12 hours, before both the dipyridamole and dobutamine studies. For both studies stress imaging was performed in the morning with a maximum difference of three hours. Coronary angiography was also performed on all patients as part of the protocol. The median (range) interval between the two stress studies was 14 (7-70) days, and the median (range) interval between the final stress study and coronary angiography was 64 (13-113) days.

The patients remained in a stable condition between the two stress studies and between the last radionuclide study and the coronary angiography. Medications were consistent throughout. The study protocol was approved by the hospital's own Ethics Committee and by the Administration of Radioactive Substances Advisory Committee, Department of Health, London. All patients gave written informed consent to the study.

\section{DOBUTAMINE STRESS STUDY}

After baseline recording of heart rate, blood pressure, and 12 lead electrocardiogram, intravenous dobutamine was given through an infusion pump as described in previous reports. ${ }^{8-10}$ The dose was increased from $5 \mu \mathrm{g} /$ $\mathrm{kg} / \mathrm{min}$ to a maximum of $20 \mu \mathrm{g} / \mathrm{kg} / \mathrm{min}$, by increments of 2.5 to $5 \mu \mathrm{g} / \mathrm{kg} / \mathrm{min}$ at five minute intervals as titrated by the heart rate response. Most patients received dobutamine by increments of $2.5 \mu \mathrm{g} / \mathrm{kg} / \mathrm{min}$. The heart rate and rhythm were monitored throughout the study period. The blood pressure was measured every minute by an automated oscillometric system (Dinamap Monitor model 1846SX, Critikon). A 12 lead electrocardiogram was recorded every three minutes.

The infusion was continued until one of the following end points was reached: (a) attainment of the maximum dose, (b) development of anginal type chest pain, (c) development of frequent or complex ventricular arrhythmias, (d) development of planar or downsloping ST segment depression more than $1.5 \mathrm{~mm} 80 \mathrm{~ms}$ after the J point. When an end point was reached, 74 $\mathrm{MBq}$ of thallium-201 were injected intravenously and imaging was performed.

DIPYRIDAMOLE STRESS STUDY

After baseline recording of heart rate and blood pressure, dipyridamole $(0.56 \mathrm{mg} / \mathrm{kg})$

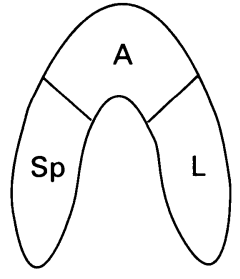

HLA

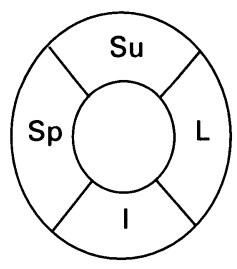

SA

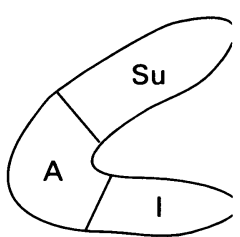

VLA
Figure 1 Schematic representation of myocardial segments. The apical $(A)$, inferior (I) lateral $(L)$, septal $(S p)$, and superior $(S u)$ segments are depicted in three projections, the horizontal long axis (HLA), the short axis $(S A)$, and the vertical long axis (VLA). was slowly infused intravenously at a rate of $0 \cdot 14 \mathrm{mg} / \mathrm{kg} / \mathrm{min}$ for four minutes. ${ }^{11}$ The heart rate and rhythm were monitored continuously throughout the study period. The blood pressure was measured at intervals of two minutes by means of the oscillometric system already described. As soon as the dipyridamole infusion was completed, the patient performed light handgrip exercise for two minutes after which $74 \mathrm{MBq}$ of thallium-201 were injected and imaging was performed.

\section{THALLIUM SPECT IMAGING}

Images were acquired immediately after pharmacological stress by means of a rotating single crystal Anger gamma camera (International General Electric Company) fitted with a low energy high sensitivity collimator. Thirty two views were obtained for 20 seconds each in a 180 degree arc extending from the 45 degree right anterior oblique to the 45 degree left posterior oblique position. The redistribution images were acquired after four hours rest and the 32 views were obtained for 30 seconds each.

The projection images were collected in a $64 \times 64$ matrix on a computer system (Nodecrest System 5, Bartec Medical Systems, Farnborough, England). Each of the projections was corrected for non-uniformity with a flood image containing 30 million counts. Axial slices were reconstructed with standard filtered back projection techniques incorporating interplanar smoothing (Bartec Medical Systems).

The reconstructed tomographic slices were reoriented into oblique planes parallel and perpendicular to the long axis of the left ventricle. Three slices were generated in each of the horizontal long axis and vertical long axis planes and four in the short axis plane ensuring alignment of stress and redistribution slices. The stress and redistribution images for each orientation were displayed simultaneously on a colour monitor for interpretation.

\section{INTERPRETATION OF RADIONUCLIDE IMAGES}

Figure 1 shows that there were three segments in the horizontal long axis projection (apical, septal, lateral), four in the short axis projection (septal, superior, inferior, lateral), and three in the vertical long axis projection (superior, apical, inferior).

The segments were independently scored by two of us (JLC, SH) blinded to the pharmacological agent used for that study, and the scores were averaged. A four point scoring system was used where $0=$ no perfusion, $1=$ severely reduced perfusion, $2=$ mildly reduced perfusion, and $3=$ normal perfusion. Each segment is represented in two planes, the apex in the horizontal and the vertical long axis, the septum and the lateral segment in the horizontal long axis and the short axis, and the superior and inferior segments in the short axis and vertical long axis. Each segment could therefore have a maximum score of 6 in each study. The scores for each set of images were summed to give a total score; a 
maximum score of 30 would indicate normal perfusion in all segments in that study. The degree of reversibility was calculated from the formula:

Reversibility score $=$ redistribution score - stress score

There was excellent agreement between observers in scoring the tomographic images as assessed by the kappa statistic ${ }^{12}(0.78$ for stress and $0 \cdot 8$ for redistribution images).

\section{CORONARY ANGIOGRAPHY}

Angiography was performed in all patients through the femoral artery by the Judkins technique. Multiple views of both coronary arteries were obtained. The angiograms were scored, with the system devised by Leaman $e t$ $a l,{ }^{13}$ by two of us (EBK, CPA) blinded to the results of the thallium scans. In this system, the coronary arteries are subdivided into segments and each segment is assigned a score that is multiplied by 5 if the vessel is totally occluded, by 3 for stenosis of $90 \%-99 \%$, and by 1 for $70 \%-89 \%$ stenosis. The segmental scores are summed to give the total coronary score. A high total score indicates a greater degree of obstructive coronary disease whereas a score of zero indicates no obstructive disease.

\section{STATISTICAL ANALYSIS}

The data were analysed with the statistical package EPI Info Version 5.0 (Centers for Disease Control, Atlanta, Georgia). Differences were compared by an appropriate $t$ test and $<0.05$ was considered significant. All data are expressed as mean (SD).

\section{Results}

CLINICAL DATA

Dipyridamole was infused four minutes in all patients, whereas dobutamine infusion took much longer (31 (5.4)) (range 18.5-40) minutes. Figure 2 shows that adverse effects were experienced by six patients $(20 \%)$ in the dipyridamole study compared with 21 patients $(70 \%)$ in the dobutamine study $\left(\chi^{2}=\right.$ $15 \cdot 15, \mathrm{p}<0.0001)$. The test order did not make any significant difference to the frequency of these adverse effects. Figure 3 shows that ST segment depression was seen in two patients $(7 \%)$ during the dipyridamole infusion and in 14 patients $(47 \%)$ during the dobutamine infusion $\left(\chi^{2}=12 \cdot 27, \mathrm{p}<0.001\right)$.

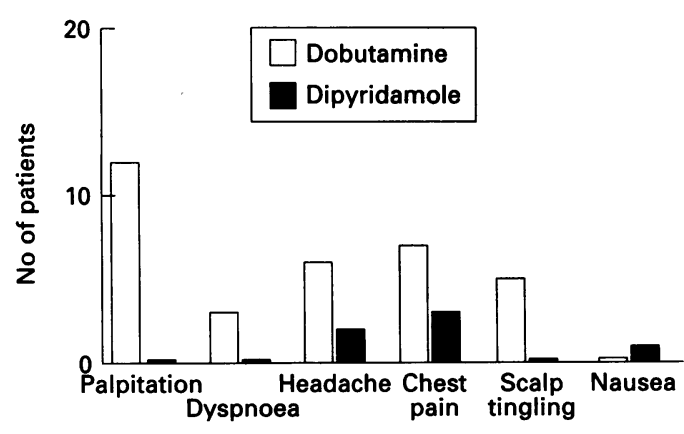

Figure 2 Number of patients who experienced an adverse effect during dipyridamole or dobutamine study.

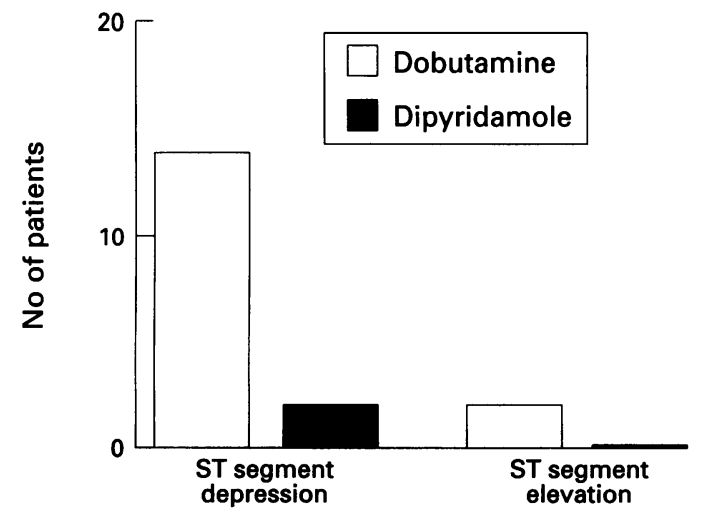

Figure 3 Number of patients with ST segment depression or elevation during dipyridamole or dobutamine study.

The dobutamine infusion was discontinued at $17.5 \mu \mathrm{g} / \mathrm{kg} / \mathrm{min}$ in three patients because of chest pain and at $15 \mu \mathrm{g} / \mathrm{kg} / \mathrm{min}$ in one because of significant ST segment depression; the remaining patients all received the maximum dosage. The heart rate at the end of the infusion was less than 100 beats/min in nine patients, six of whom had not discontinued $\beta$ blockers before the study.

Dobutamine caused a significantly greater change in heart rate and systolic blood pressure than dipyridamole $(p<0.01)$, with or without the addition of a hand grip exercise (fig 4).

No patient required medication to control an adverse effect.

\section{COMPARATIVE COSTS}

The cost of dobutamine, dextrose, and associated infusion equipment was $£ 17 /$ patient, whereas the cost of dipyridamole and infusion equipment was $£ 1.50$ /patient, giving an extra cost of $£ 15 \cdot 50$ for a dobutamine study.

\section{THALLIUM-201 IMAGING DATA}

Table 1 summarises the difference between dipyridamole and dobutamine for total and regional scores for the stress, redistribution, and reversibility studies. The values are shown as the mean difference between the dipyridamole and the dobutamine score. A negative value means a lower score and hence more defects with dipyridamole whereas a positive value means more defects with dobutamine.

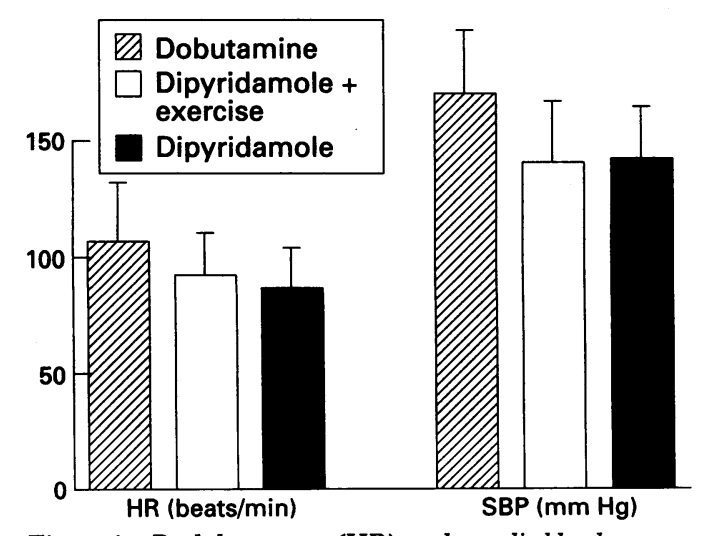

Figure 4 Peak heart rate (HR) and systolic blood pressure (SBP) during dobutamine study, and dipyridamole study with and without hand grip exercise. 
Table 1 Mean (SD) difference (dipyridamole - dobutamine) for stress, redistribution, and reversibility

\begin{tabular}{llrl}
\hline Region & \multicolumn{1}{l}{ Stress } & Redistribution & \multicolumn{1}{c}{ Reversibility } \\
\hline Apex & $-0.63(1.53)^{\star}$ & $-0.03(0.60)$ & $0.60(1.21)^{\star}$ \\
Septum & $0.22(1.10)$ & $-0.05(0.86)$ & $-0.22(1.30)$ \\
Lateral & $-0.37(0.89)^{\star}$ & $-0.10(0.65)$ & $0.28(0.77)$ \\
Superior & $0.42(1.33)$ & $0.12(0.61)$ & $-0.18(1.16)$ \\
Inferior & $0.23(1.19)$ & $0.07(1.10)$ & $-0.17(0.19)$ \\
Total & $-0.30(3.73)$ & $-0.20(2.38)$ & $0.17(3.62)$ \\
\hline
\end{tabular}

${ }^{\star} \mathrm{p}<0 \cdot 05$. Reversibility $=$ Redistribution - Stress.
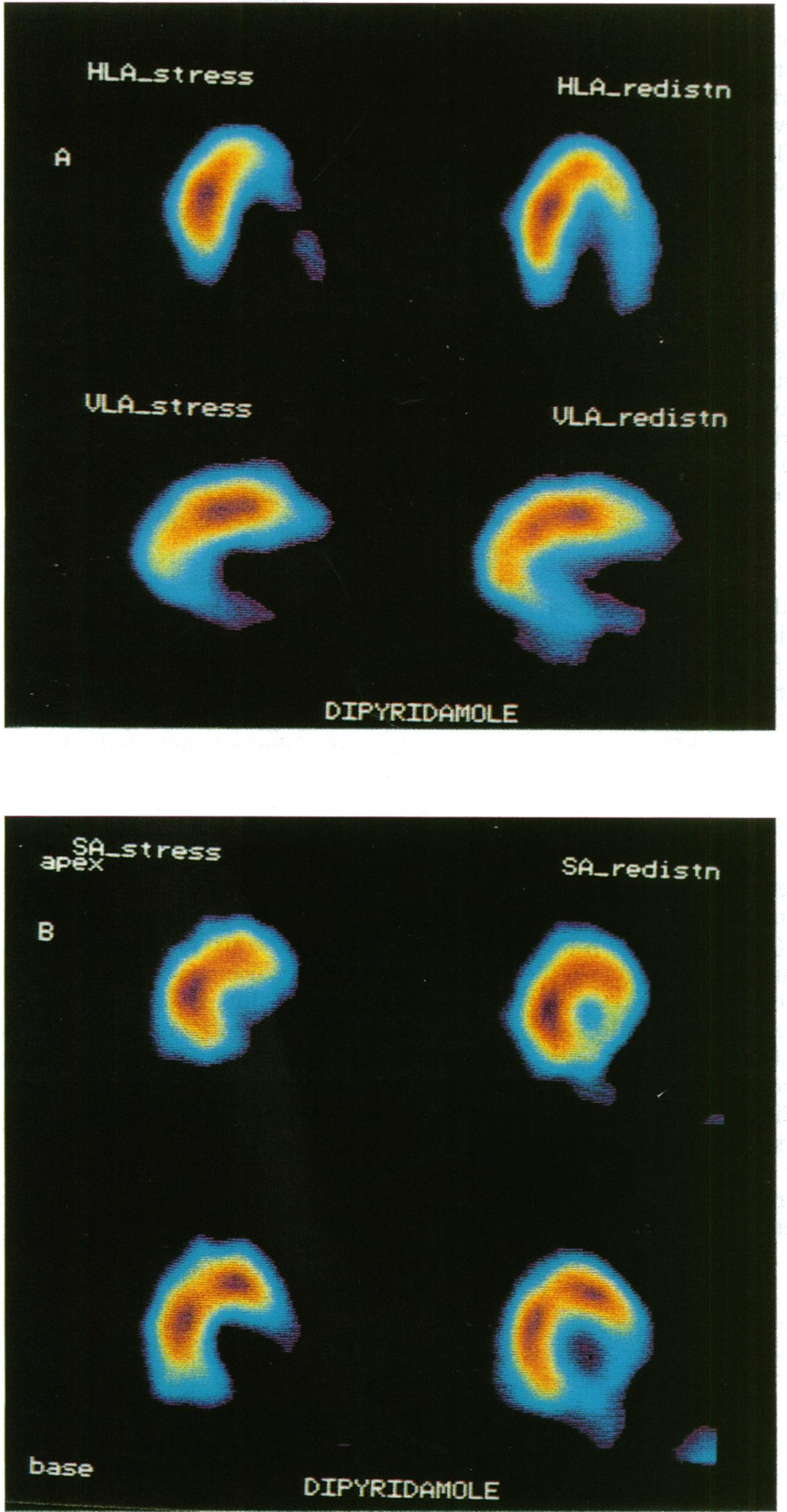

Figure 5 Example of stress and redistribution scans during dipyridamole study. On the stress images a perfusion defect is seen in the lateral to inferior segments, extending from base to apex, with some redistribution (redistn) after four hours. $(A)$ Images from the horizontal long axis (HLA) and the vertical long axis (VLA). (B) Images from the short axis $(S A)$.
There was no significant difference between the two studies in total stress, total redistribution, or total reversibility scores. Segmental analysis, however, indicated that dipyridamole produced more defects in the apical and lateral segments $(p<0.05)$ and more reversibility at the apex $(p<0.05)$. There was no difference between the studies in terms of stress or reversibility scores for the septal, superior, and inferior segments. The segmental redistribution scores were not significantly different in the two studies.

Figure 5 shows representative stress and redistribution scans in a dipyridamole study. A perfusion defect is seen extending from base to apex with some redistribution after four hours. Figure 6 shows stress and redistribution scans in a dobutamine study performed on the same patient. A smaller perfusion defect is evident with no definite redistribution after four hours. Both figures were set to the same background and saturation levels relative to the maximum pixel count in the image. The higher background activity seen on the dobutamine images was not a significant finding.

CORONARY ARTERY SCORE

Nine patients had no structural lesions of the coronary artery at angiography, four had single vessel disease, 11 had two vessel disease, and six had triple vessel disease. Table 2 shows that there was better correlation between the total stress score and the total coronary score for dipyridamole $(r=0.81$, $\mathrm{p}<0.001)$ than for dobutamine $(r=0.64$, $\mathrm{p}<0.001)$.

In the six patients who had continued to take $\beta$ blockers during the studies, there was poor correlation with the coronary score in the dobutamine study $(r=0.34$, NS), but not in the dipyridamole study $(r=0.83, \mathrm{p}<0.05$, table 3).

Table 2 also shows that the redistribution score correlated well with the coronary score for both drugs (dipyridamole $r=0.67, \mathrm{p}<$ 0.001 ; dobutamine $r=0.62, \mathrm{p}<0.001)$.

Table 4 shows the correlation between the regional stress and redistribution scores for individual segments and the corresponding coronary artery score. The superior and septal segments were correlated with the left

Table 2 Correlation coefficient (95\% CI) of dipyridamole and dobutamine scores with coronary score

\begin{tabular}{|c|c|c|}
\hline Study & Stress & Redistribution \\
\hline $\begin{array}{l}\text { Dipyridamole } \\
\text { Dobutamine }\end{array}$ & $\begin{array}{l}0.81(0.62 \text { to } 0.90)^{\star} \\
0.64(0.36 \text { to } 0.81)^{\star}\end{array}$ & $\begin{array}{l}0.67(0.40 \text { to } 0.83)^{\star} \\
0.62(0.33 \text { to } 0.80)^{\star}\end{array}$ \\
\hline \multicolumn{3}{|c|}{${ }^{\star} \mathrm{p}<0.001$ for correlation coefficient. } \\
\hline \multicolumn{3}{|c|}{$\begin{array}{l}\text { Table } 3 \text { Effect of } \beta \text { blockers on correlation of stress scores } \\
\text { with coronary score }\end{array}$} \\
\hline Study & $\beta$ blocker (n) & Correlation coefficient \\
\hline Dipyridamole & $\begin{array}{l}+6 \\
-24 \\
+6 \\
-24\end{array}$ & $\begin{array}{l}0.83^{\star} \\
0.78 \dagger \\
0.34 \\
0.62 \ddagger\end{array}$ \\
\hline
\end{tabular}

${ }^{\star} \mathrm{p}<0.05 ; \mathrm{tp}<0.001 ; \neq \mathrm{p}<0.01$. 

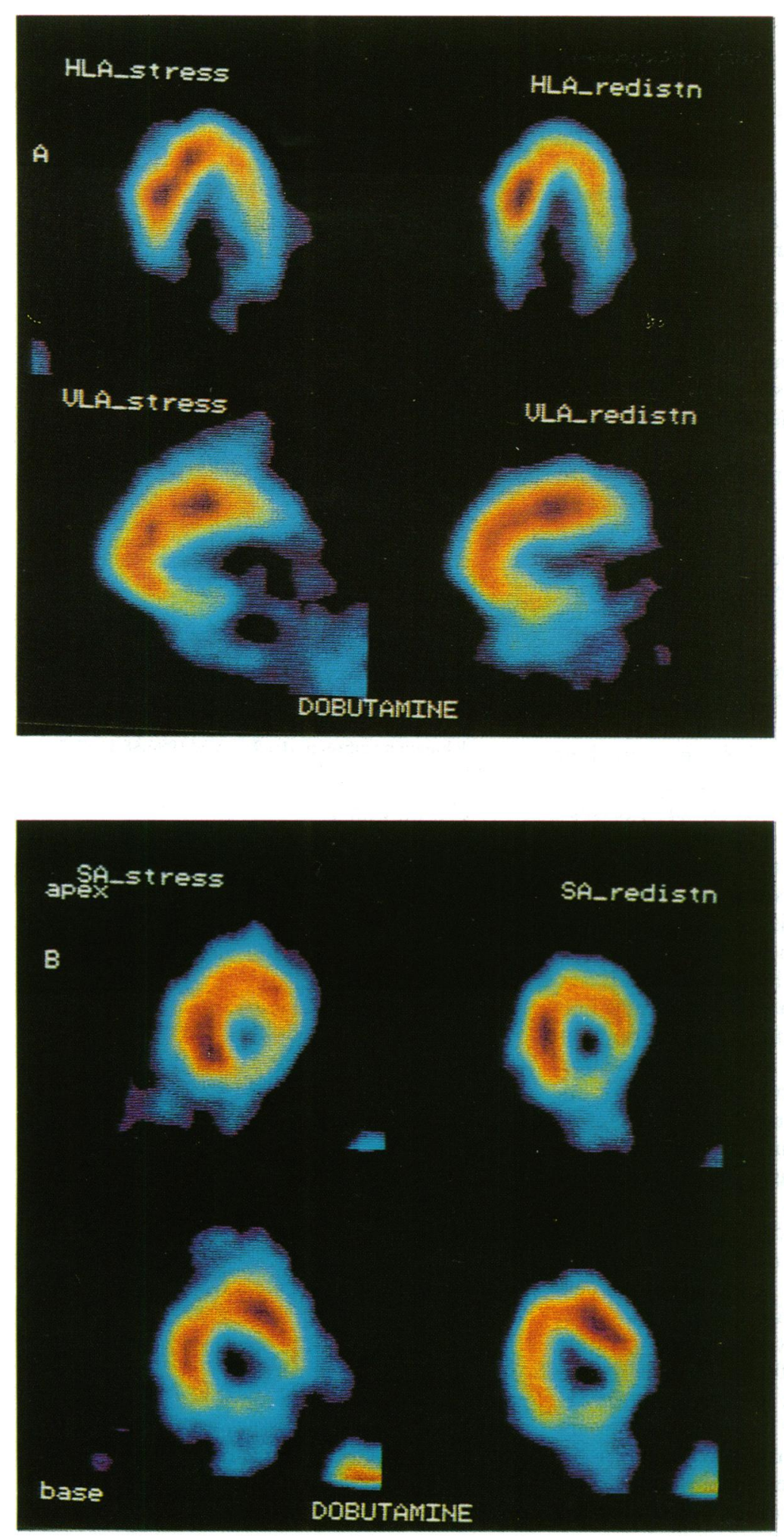

Figure 6 Example of stress and redistribution scans during dobutamine study in the same patient. A smaller perfusion defect is seen in the stress image with no definite redistribution (redistn) after four hours. (A) Images from the horizontal long axis (HLA) and the vertical long axis (VLA). (B) Images from the short axis $(S A)$. anterior descending artery score, the lateral segment with the circumflex artery score, and the inferior segment with the right coronary artery score. The apical segment was not studied in this way because the apex often has dual supply from the left anterior and right coronary arteries.

The regional stress score correlated better with the corresponding coronary artery score with dipyridamole than with dobutamine. The regional redistribution score correlation between the lateral and inferior segments and corresponding coronary artery score was also better with dipyridamole. The superior segment redistribution score did not correlate with the left anterior descending artery score in either study.

\section{Discussion}

Previous studies have shown the usefulness of dobutamine stress testing in the detection of coronary artery disease, in conjunction with electrocardiography, ${ }^{89}$ cross sectional echocardiography, ${ }^{7}$ or thallium-201 scintigraphy. ${ }^{8}$

Dobutamine increases oxygen demand in a way similar to dynamic exercise as a consequence of its effects on contractility, heart rate, and systolic blood pressure. ${ }^{1014}$ Thallium perfusion defects detected under dobutamine stress probably do represent areas of myocardial ischaemia. Dipyridamole, on the other hand, produces coronary vasodilatation, with little "myocardial stress" as defined by changes in rate-pressure product and development of myocardial ischaemia. Perfusion abnormalities detected with this technique are thought to represent areas of altered blood flow rather than areas of ischaemia. ${ }^{515}$ Despite this apparent disadvantage, this study indicates that both drugs are equally capable of provoking myocardial perfusion defects, with the dipyridamole technique proving to be more effective in producing segmental defects, particularly in the apical and lateral regions. This difference between the two techniques is unlikely to be due to simple extrinsic factors such as, for example, breast attenuation, as these factors would be present in both studies. Thallium-201 is distributed to the myocardium in relation to the regional blood flow and therefore does not require ischaemia to produce differences in perfusion. Dipyridamole may be a better stressing agent because it causes up to a five fold increase in flow in normal coronary arteries. This magnitude of differential flow between normal and ischaemic territories may be difficult to achieve with dobutamine stress.

Table 4 Correlation coefficient (95\% CI) of segmental stress and redistribution scores with coronary artery score

\begin{tabular}{|c|c|c|c|c|c|}
\hline \multirow{2}{*}{$\begin{array}{l}\text { Coronary } \\
\text { artery }\end{array}$} & \multicolumn{3}{|c|}{ Dipyridamole } & \multicolumn{2}{|l|}{ Dobutamine } \\
\hline & Segment & Stress & Redistribution & Stress & Redistribution \\
\hline $\begin{array}{l}\text { LAD } \\
\text { LAD } \\
\text { CX } \\
\text { RCA }\end{array}$ & $\begin{array}{l}\text { Septum } \\
\text { Superior } \\
\text { Lateral } \\
\text { Inferior }\end{array}$ & $\begin{array}{l}0.54(0.23 \text { to } 0.76)^{\star} \\
0.41(0.05 \text { to } 0.67)^{\star} \\
0.63(0.34 \text { to } 0.81)^{\star} \\
0.73(0.51 \text { to } 0.87)^{\star}\end{array}$ & $\begin{array}{l}0.60(0.31 \text { to } 0.79)^{\star} \\
0.15(-0.22 \text { to } 0.49) \\
0.55(0.23 \text { to } 0.76)^{\star} \\
0.68(0.43 \text { to } 0.84)^{\star}\end{array}$ & $\begin{array}{l}0.53(0.21 \text { to } 0.75)^{\star} \\
0.20(0.17 \text { to } 0.52) \\
0.55(0.24 \text { to } 0.76)^{\star} \\
0.59(0.29 \text { to } 0.78)^{\star}\end{array}$ & $\begin{array}{l}0.60(0.30 \text { to } 0.79)^{\star} \\
0.18(-0.20 \text { to } 0.50) \\
0.48(0.15 \text { to } 0.72)^{\star} \\
0.61(0.31 \text { to } 0.79)^{\star}\end{array}$ \\
\hline
\end{tabular}

${ }^{\star} \mathrm{p}<0.05$. LAD, left anterior descending artery; CX, left circumflex artery; RCA, right coronary artery. 
Previous reports have indicated that both techniques have a high sensitivity and specificity for the detection of multivessel coronary artery disease. ${ }^{911}$ Although there was a long interval between the final stress study and coronary angiography in some patients, a good correlation was none the less seen between the total stress and total redistribution score and the coronary angiographic score in both studies. In the dobutamine study, however, concurrent $\beta$ blocker medication had an adverse effect on this correlation and it is therefore preferable that these drugs be withdrawn a few days before the dobutamine infusion. This must be regarded as a serious disadvantage of this technique, in view of the well known risks associated with stopping such medication in patients with ischaemic chest pain. ${ }^{1617}$ Discontinuing $\beta$ blockers did not influence the dipyridamole study, a finding generally in agreement with the recent report of Bridges $e t a l^{18}$ and earlier studies. ${ }^{219}$

Table 1 shows that there were no significant differences in redistribution scores between dipyridamole and dobutamine. This suggests that there are no differences in their ability to differentiate infarction and reversible ischaemia in areas of previous infarction. The study was not, however, designed to investigate this problem and a further study would be required.

A dobutamine study is considerably more expensive than a dipyridamole study. The dobutamine infusion is lengthy and adverse effects such as chest pain, dyspnoea, and palpitations occur significantly more often, as seen in this study. These adverse effects limit its usefulness as a pharmacological stressing agent and constitute a further disadvantage of the technique. Dipyridamole, on the other hand, causes little change in heart rate or blood pressure, and was associated with few adverse effects in this study.

In conclusion, graded doses of intravenous dobutamine can be used to provoke myocardial ischaemia for thallium imaging. It is, however, no more effective than dipyridamole at provoking overall perfusion defects and is less effective at the apex and the lateral segment. Furthermore, the technique is more expensive, more time consuming, and is associated with more adverse effects than dipyridamole. It cannot therefore be recommended as an alternative to dipyridamole in the assessment of ischaemic heart disease by thallium scintigraphy.

We thank Ian Brabiner, Gill Marston, Jill Ward, and Carole Smith for technical help and Susan Knowles for assistance in preparation of the typescript.

EBK was supported by the Hull and East Riding Cardiac Trust Fund.

1 Beller GA. Dipyridamole thallium-201 scintigraphy: an excellent alternative to exercise scintigraphy. $7 \mathrm{Am}$ Coll Cardiol 1989;14:1642-4.

2 Leppo JA, Boucher CA, Okada RD, Newell JB, Strauss HW, Pohost GM. Serial Thallium-201 myocardial maging after dipyridamole infusion: diagnostic utility in detecting coronary stenoses and relationship to regional wall motion. Circulation 1982;66:649-57.

3 Chambers CE, Brown KA. Dipyridamole-induced ST segment depression during thallium-201 imaging in patients with coronary artery disease: angiographic and hemodynamic determinants. $\mathcal{F} \mathrm{Am}$ Coll Cardiol 1988;12 $37-41$.

4 Iskandrian AS, Heo J. Myocardial ischemia during pharmacologic coronary vasodilatation: a concept in search of definition. Cathet Cardiovasc Diagn 1989;18:65-6.

5 Wackers FJ. Pharmacological stress with dipyridamole: how lazy can one be [editorial]? F Nucl Med 1990;31: 1024-7.

6 Mannering D, Cripps T, Leech G, et al. The dobutamine stress test as an alternative to exercise testing after acute myocardial infarction. Br Heart 7 1988;59:521-6.

7 Berthe C, Pierard LA, Hiernaux M, et al. Predicting the extent and location of coronary artery disease in acute myocardial infarction by echocardiography durin dobutamine infusion. Am f Cardiol 1986;58:1167-72.

8 Mason JR, Palac RT, Freeman ML, et al. Thallium scintigraphy during dobutamine infusion: non exercisedependent screening test for coronary disease. Am Hear f 1984;107:481-5.

9 Coma-Canella I. Sensitivity and specificity of dobutamine electrocardiography test to detect multivessel disease after acute myocardial infarction. Eur Heart $\mathcal{f} 1990$ 11:249-57.

10 Freeman ML, Palac R, Mason J, et al. A comparison of dobutamine infusion and supine bicycle exercise for radionuclide cardiac stress testing. Clin Nucl Med 1984; 9:251-5.

11 Lepo JA. Dipyridamole-thallium imaging: the lazy man's stress test. $\mathcal{F}$ Nucl Med 1989;30:281-7.

$12 \mathrm{Ker} M$. Issues in the use of kappa. Invest Radiol 1991;26:78-83.

13 Leaman DM, Brower RW, Meester GT, Serruys P, Van den Brand $M$. Coronary artery atherosclerosis: severity of the disease, severity of angina pectoris and compromised left ventricular function. Circulation 1981;63: 285-92.

14 Meyer L, Curry GC, Donsky MS, Twieg DB, Parkey $\mathrm{RW}$, Willerson JT. Influence of dobutamine on hemodynamics and coronary blood flow in patients with and without coronary artery disease. Am f Cardiol 1976; 38:103-8.

15 Zeller FP, Blend MJ. The use of intravenous dipyridamole in Thallium 201 myocardial perfusion imaging. Pharmacotherapy 1987;7:178-84.

16 Wood AJJ. Beta-blocker withdrawal. Drugs 1983;25: 318-21.

17 Miller RR, Olson HG, Amsterdam EA, Mason DT Propranolol withdrawal phenomenon. $N$ Engl $f \mathrm{Med}$ 1975;293:416-8.

18 Bridges AB, Kennedy N, McNeill GP, Cook B, Pringle TH. The effects of atenolol on dipyridamole $201 \mathrm{~T} 1$ TH. The effects of atenolol on dipyridamole $201 \mathrm{~T} 1$ myocardial perfusion tomography in patients with coro-

19 Bonaduce D, Muto P, Morgano G, et al. Effect of beta blocker on thallium-201 dipyridamole myocardial scintigraphy. Acta Cardiol 1984;39:399-408. 